\title{
KAJIAN KONDISI JALUR PEJALAN KAKI DI DALAM KAWASAN KAMPUS UNIVERSITAS BENGKULU
}

\author{
Panji Anom Ramawangsa ${ }^{1}$, Atik Prihatiningrum ${ }^{2}$, Besperi ${ }^{3}$ \\ ${ }^{1,2}$ Program Studi Arsitektur, Fakultas Teknik, Universitas Bengkulu, Jl. WR. Supratman, Kandang \\ Limun, Kec. Muara Bangka Hulu, Bengkulu 38371 \\ ${ }^{3}$ Jurusan Teknik Sipil, Universitas Bengkulu, Jl. WR. Supratman, Kandang Limun, Kec. Muara Bangka \\ Hulu, Bengkulu 38371 \\ Panjianom89@gmail.com
}

\section{Diterima: 23-02-2020Ｄireview : 24-02-2020Ｄirevisi: 29-04-2020_Disetujui: 05-05-2020}

\begin{abstract}
ABSTRAK. Berjalan kaki merupakan kegiatan yang esensial dalam menikmati suatu wilayah sekaligus moda transportasi yang alami dan tanpa emisi. Berdasarkan observasi awal peneliti, ditemukan pada kawasan Universitas Bengkulu tidak tersedia jalur pejalan kaki, jalur pejalan kaki yang terputus, serta jalur pejalan kaki yang tidak memenuhi standar. Sehingga untuk mewujudkan jalur pejalan kaki yang memenuhi standar dan mendorong aktivitas berjalan kaki di dalam kampus maka dibutuhkan jalur pejalan kaki yang sesuai standar dan walkable. Teknik pengumpulan data dan informasi primer pada penelitian ini meliputi teknik observasi dan kuesioner untuk mengkaji tingkat aktifitas pejalan kaki di kawasan kampus. Berdasarkan penilaian yang telah dilakukan, ditemukan bahwa pada segmen 1 merupakan area dengan kondisi jalur pedestrian yang telah tersedia sesuai standar dan berfungsi dengan baik dan pada segmen 2 merupakan area yang memiliki permasalahan jalur pejalan kaki yang tidak sesuai standar sehingga perlu beberapa solusi yang tepat untuk meningkatkan kondisi jalur pejalan kaki.
\end{abstract}

Kata kunci: Kampus, Observasi, Jalur Pejalan Kaki

ABSTRACT. Walking is an essential activity in enjoying an area as well as a mode of transportation that is natural and without emissions. Based on the researchers' preliminary observations, it was found that there were no pedestrian paths in the University of Bengkulu area, broken pedestrian paths, and pedestrian paths that did not meet standards. To realize pedestrian paths that meet the criteria and encourage walking activities on campus, pedestrian paths appropriate to the standard and walkable are needed. This study's primary data and information collection techniques include observation and questionnaire techniques to assess the level of pedestrian activity in the campus area. Based on the assessment that has been done, it was found that in segment 1 is an area with pedestrian track conditions that have been available according to the standard and functioning correctly. Segment 2 is an area with pedestrian path problems that are not following standards, so it needs some appropriate solutions to improve pedestrian path conditions.

Keywords: Campus, Observation, Pedestrian Way

\section{PENDAHULUAN}

Jalur pejalan kaki merupakan ruang terbuka yang mewadahi sirkulasi atau perpindahan orang dari titik asal ke tujuan yang akan dicapai. Ketersediaan jalur pejalan kaki di ruas jalan dengan kondisi yang aman, nyaman, tanpa hambatan mendorong orang untuk tertarik berjalan kaki karena kondisi jalur pejalan kaki menentukan mobilitas pejalan kaki dalam mencapai tujuan (Auf dkk., 2015)

Universitas Bengkulu memiliki karakteristik lingkungan di pesisir pantai yang menjadikan jalur pejalan kaki di dalam kawasan kampus sangat penting untuk direncanakan sesuai aspek keamanan bagi pejalan kaki. Universitas Bengkulu berada pada peringkat ke-26 dari 66 perguruan tinggi se-Indonesia pada tahun 2018 sebagai kampus yang berkomitmen terhadap penghijauan dan keberlanjutan lingkungan yang dilakukan oleh $U I$ Greenmetric (GreenMetric, 2019). Salah satu indikator pemeringkatan yang dilakukan $U I$ Greenmetric mengenai sistem transportasi yang merupakan peran penting dalam tingkat emisi karbon dan polutan di kawasan kampus. Berdasarkan observasi awal peneliti, ditemukan kawasan yang tidak tersedia jalur pejalan kaki, jalur pejalan kaki yang terputus, serta jalur pejalan kaki yang tidak standar. 
Untuk mewujudkan jalur pejalan kaki yang memenuhi standar dan mendorong aktivitas berjalan kaki di dalam kampus, terdapat beberapa hal yaitu tersedianya jalur pejalan kaki yang sesuai standar dan walkable, sebab kondisi fisik pada jalur pejalan kaki menjadi penentu kualitas jalur pejalan kaki itu sendiri (Handayani dkk., 2018).

Penelitian ini bertujuan untuk mengetahui kondisi jalur pejalan kaki yang ada di dalam kawasan kampus Universitas Bengkulu berdasarkan persyaratan teknis jalur pejalan kaki sesuai standar yang mampu berintegrasi antar area serta menghubungkan pusat kegiatan.

\section{Persyaratan Teknis Jalur Pejalan Kaki}

Menurut Peraturan Menteri Pekerjaan Umum Nomor : 03/PRT/M/2014, jaringan pejalan kaki merupakan ruas pejalan kaki yang terintegrasi secara terpisah dengan jalan, yang diperuntukan untuk prasarana dan sarana pejalan kaki dan menghubungkan pusat kegiatan atau fasilitas pergantian moda. (Patent No. Nomor : 03/PRT/M/204, 2014)

Syarat-syarat penyediaan sarana pejalan kaki yang memenuhi faktor keseimbangan, kenyamanan dan keselamatan (Anggriani, 2009) adalah sebagai berikut :

1. Lebar minimum jalur pejalan kaki untuk satu arah adalah $136 \mathrm{~cm}$ dan untuk jalur dua arah minimum $180 \mathrm{~cm}$. khusus penyandang cacat, jalur ini harus bebas rambu-rambu, benda pelengkap jalan, dan pohon tiang yang menghalang.

2. Kemiringan maksimum 7 derajat bagi penyandang cacat.

3. Permukaan pejalan kaki harus kuat, tahan cuaca dengan permukaan halus, tidak licin dan stabil. Apabila terdapat gundukan pada jalur pejalan kaki tingginya tidak lebih $1,25 \mathrm{~cm}$.

4. Terdapat area istirahat setiap 180 meter pada jalur pejalan kaki.

5. Memiliki sumber pencahayaan buatan pada malam hari dengan intensitas cahaya 50-150 lux.

6. Memiliki tepi pengaman dengan tinggi minimum $10 \mathrm{~cm}$ dan lebar $15 \mathrm{~cm}$ pada sepanjang jalur pedestrian.

7. Terdapat jalur pemisah $30 \mathrm{~cm}$ antara jalur pejalan kaki dengan jalan raya.

\section{METODE PENELITIAN}

Lokasi penelitian dilakukan di dalam kawasan kampus Universitas Bengkulu Jalan W.R Supratman, Kelurahan Kandang Limun, Kecamatan Muara Bangkahulu. Letak lokasi dan penggambaran lokasi penelitian dijelaskan pada gambar berikut.

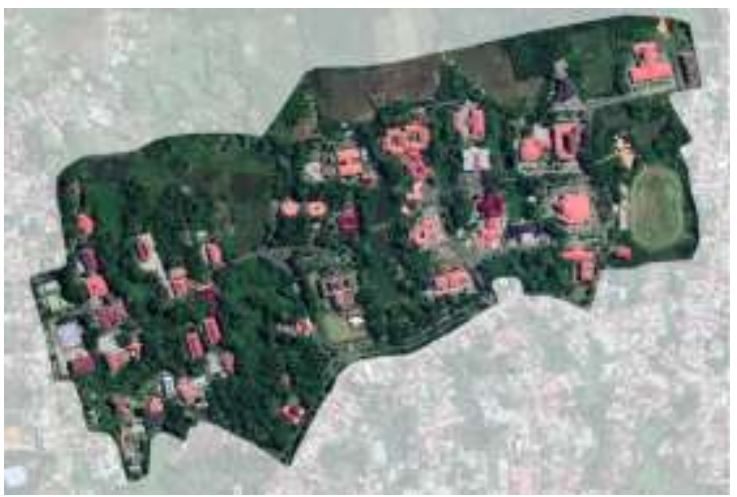

Gambar 1 Lokasi penelitian di kawasan Universitas Bengkulu

(Sumber : Google earth, 2020)

Jalur pejalan kaki yang menjadi fokus pengamatan dan analisis dari penelitian ini terdapat 10 segmen yang dapat dilihat pada gambar 2 dan tabel 1.

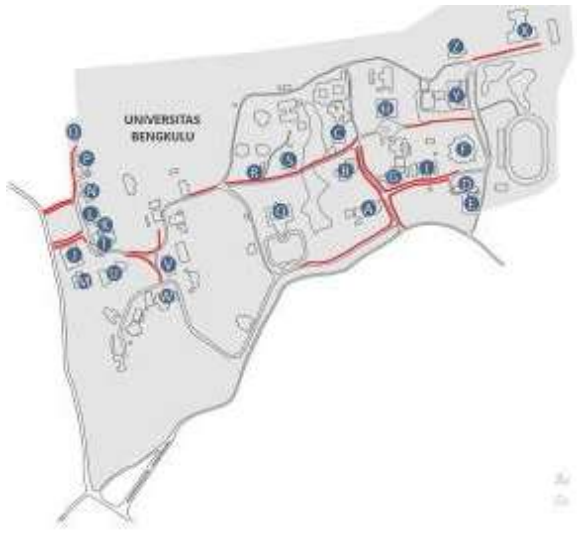

Gambar 2 Jalur pejalan kaki eksisting (Sumber : Analisis Pribadi, 2019)

Objek amatan dan analisis yang dipilih pada penelitian ini adalah sebagai berikut.

Tabel 1 Objek amatan dan lokasi

\begin{tabular}{|c|c|c|}
\hline Segmen & $\begin{array}{l}\text { Wilayah } \\
\text { Amatan }\end{array}$ & $\begin{array}{c}\text { Pusat Aktivitas Lokasi } \\
\text { Kawasan }\end{array}$ \\
\hline 1 & $\begin{array}{l}\text { Jalur } \\
\text { gerbang } \\
\text { pintu masuk } \\
\text { dari jalan } \\
\text { W.R } \\
\text { Supratman }\end{array}$ & $\begin{array}{l}\text { A. Gedung Dekanat Fisipol } \\
\text { B. Gedung Kuliah Bersama } \\
\\
\text { C. Gedung Kuliah Bersama } \\
2\end{array}$ \\
\hline 2 & $\begin{array}{l}\text { Gerbang } \\
\text { pintu keluar } \\
\text { ke jalan W.R }\end{array}$ & $\begin{array}{ll}\text { D. Gedung Dekanat } \\
\text { F.Teknik } \\
\text { E. Gedung Lab. F.Teknik }\end{array}$ \\
\hline
\end{tabular}




\begin{tabular}{|c|c|c|}
\hline & Supratman & F. Gedung Serbaguna \\
\hline 3 & $\begin{array}{l}\text { Jalur klaster } \\
\text { FKIP }\end{array}$ & $\begin{array}{ll}\text { G. } & \text { Gedung LPTIK } \\
\text { H. } & \text { Gedung Perpustakaan } \\
\text { I. } & \text { Gedung Administrasi } \\
& \text { Pascasarjana }\end{array}$ \\
\hline 4 & $\begin{array}{l}\text { Gerbang } \\
\text { pintu masuk } \\
\text { jalan Budi } \\
\text { Utomo }\end{array}$ & $\begin{array}{ll}J . & \text { Sport Center } \\
\text { K. } & \text { Gedung pascasarjana } \\
& \text { Fakultas Hukum }\end{array}$ \\
\hline 5 & $\begin{array}{l}\text { gerbang } \\
\text { pintu keluar } \\
\text { ke jalan Budi } \\
\text { Utomo }\end{array}$ & $\begin{array}{ll}\text { L. Gedung Auditorium } \\
\text { M. Gedung Dekanat } \\
\text { Fakultas Hukum } \\
\text { N. Gedung LPPM } \\
\text { O. Masjid } \\
\text { P. Gedung A } \\
\end{array}$ \\
\hline 6 & $\begin{array}{l}\text { Jalur } \\
\text { kawasan } \\
\text { Rektorat }\end{array}$ & Q. Rektorat \\
\hline 7 & $\begin{array}{l}\text { Jalur } \\
\text { kawasan } \\
\text { Danau }\end{array}$ & $\begin{array}{ll}\text { R. } & \text { Koperasi } \\
\text { S. } & \text { Gedung Jurusan } \\
& \text { Kehutanan dan } \\
& \text { Peternakan }\end{array}$ \\
\hline 8 & $\begin{array}{l}\text { Jalur klaster } \\
\text { Fakultas } \\
\text { Hukum }\end{array}$ & $\begin{array}{ll}\text { T. } & \text { Gedung Eks Rektorat } \\
\text { U. } & \text { Gedung Fakultas Hukum }\end{array}$ \\
\hline 9 & $\begin{array}{l}\text { Jalur klaster } \\
\text { Fakultas } \\
\text { Ekonomi }\end{array}$ & $\begin{array}{l}\text { V. Gedung Pusat Bahasa } \\
\text { W. Gedung Dekanat D3 } \\
\text { Akuntansi }\end{array}$ \\
\hline 10 & $\begin{array}{l}\text { Jalur klaster } \\
\text { FKIK }\end{array}$ & $\begin{array}{ll}\text { X. } & \text { Gedung Dekanat FKIK } \\
\text { Y. } & \text { Gedung Kuliah Bersama } \\
& 3 \text { \& } 4 \\
\text { Z. } & \text { Gedung Kuliah Bersama } \\
& 5\end{array}$ \\
\hline
\end{tabular}

Sumber : Hasil observasi, 2019

Teknik pengumpulan data pada penelitian ini meliputi teknik observasi dan pengukuran. Metode yang digunakan dalam observasi adalah metode observasi partisipasi pasif yaitu metode observasi yang dilakukan peneliti untuk mengumpulkan data dengan cara datang langsung ke objek yang diamati (Riani dkk, 2018). Dalam menilai observasi di lapangan menggunakan penilaian dalam bentuk scoring dengan memberi skor 1 sampai 5 ( 1 adalah skor terendah dan 5 adalah skor tertinggi) pada kondisi eksisting setiap segmen. Hasil dari penilaian tersebut untuk melihat tingkatan kualitas jalur pejalan kaki secara keseluruhan serta menjadi pertimbangan dalam arahan desain.

\section{HASIL DAN PEMBAHASAN}

Berdasarkan hasil observasi pada jalur pejalan kaki yang ada di dalam kawasan kampus Universitas Bengkulu, kondisi jalur pejalan kaki di dalam kawasan kampus Universitas Bengkulu dapat dilihat pada tabel 2.

Tabel 2 Kondisi Jalur Pejalan Kaki Di Dalam Kawasan Universitas Bengkulu

\begin{tabular}{|c|c|c|c|}
\hline $\begin{array}{c}\text { Kondisi } \\
\text { Eksisting }\end{array}$ & Indikator & $\begin{array}{c}\text { Kondisi } \\
\text { Walkability }\end{array}$ & $\begin{array}{l}\text { Sk } \\
\text { or }\end{array}$ \\
\hline $\begin{array}{l}\text { Segmen } 1 \\
\text { Gerbang pintu }\end{array}$ & $\begin{array}{l}\text { 1. Terdapat jalur } \\
\text { pemisah } 30\end{array}$ & $\begin{array}{l}\text { 1. Jalur } \\
\text { pedestrian }\end{array}$ & 5 \\
\hline
\end{tabular}

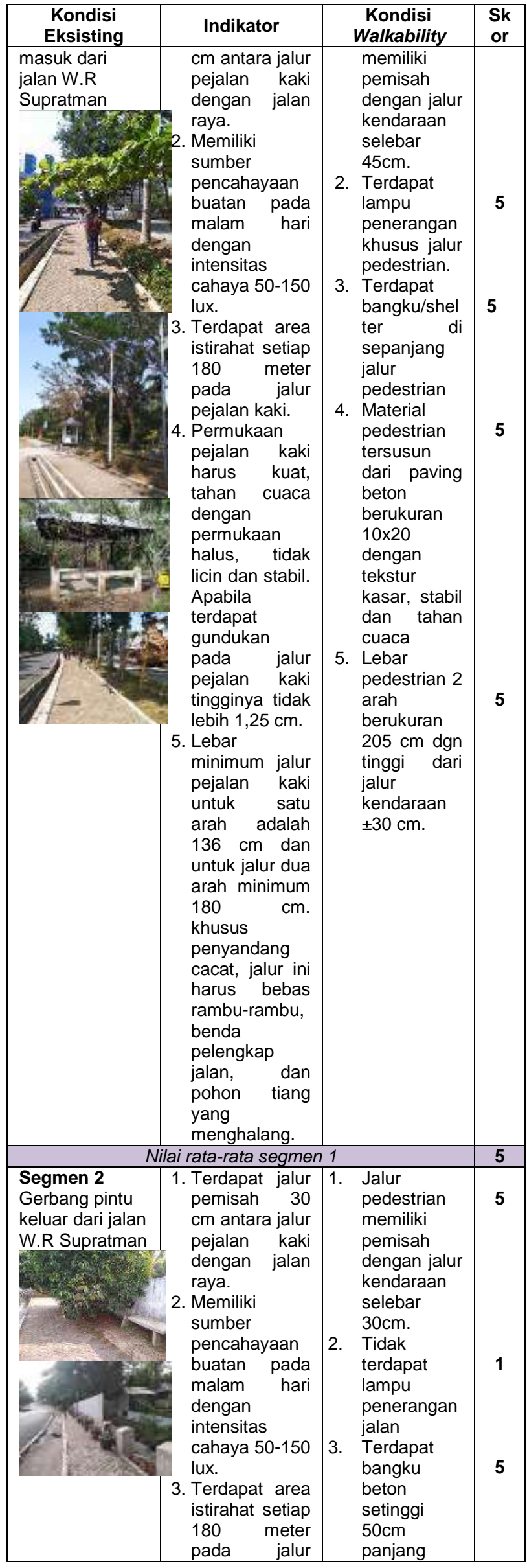




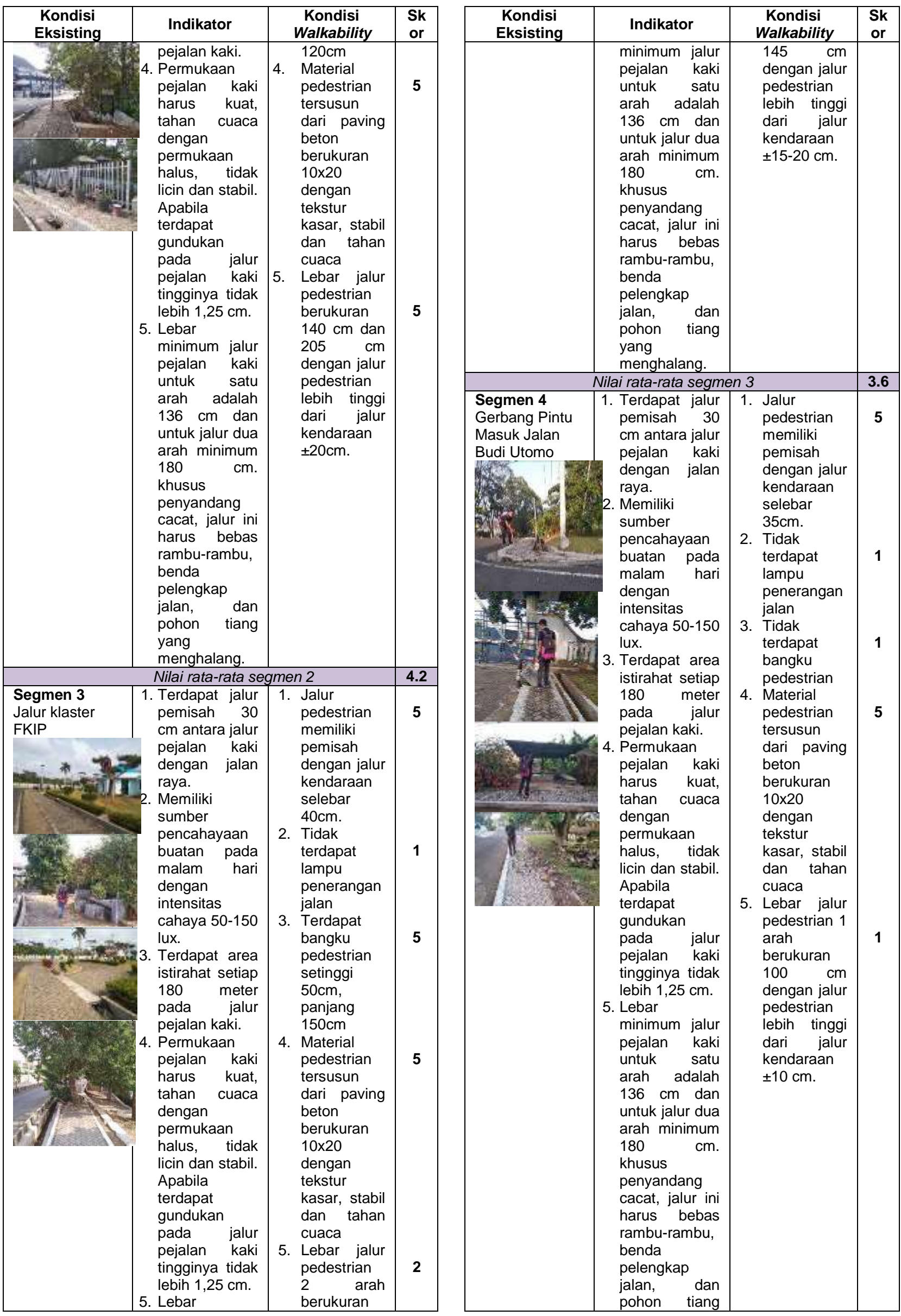




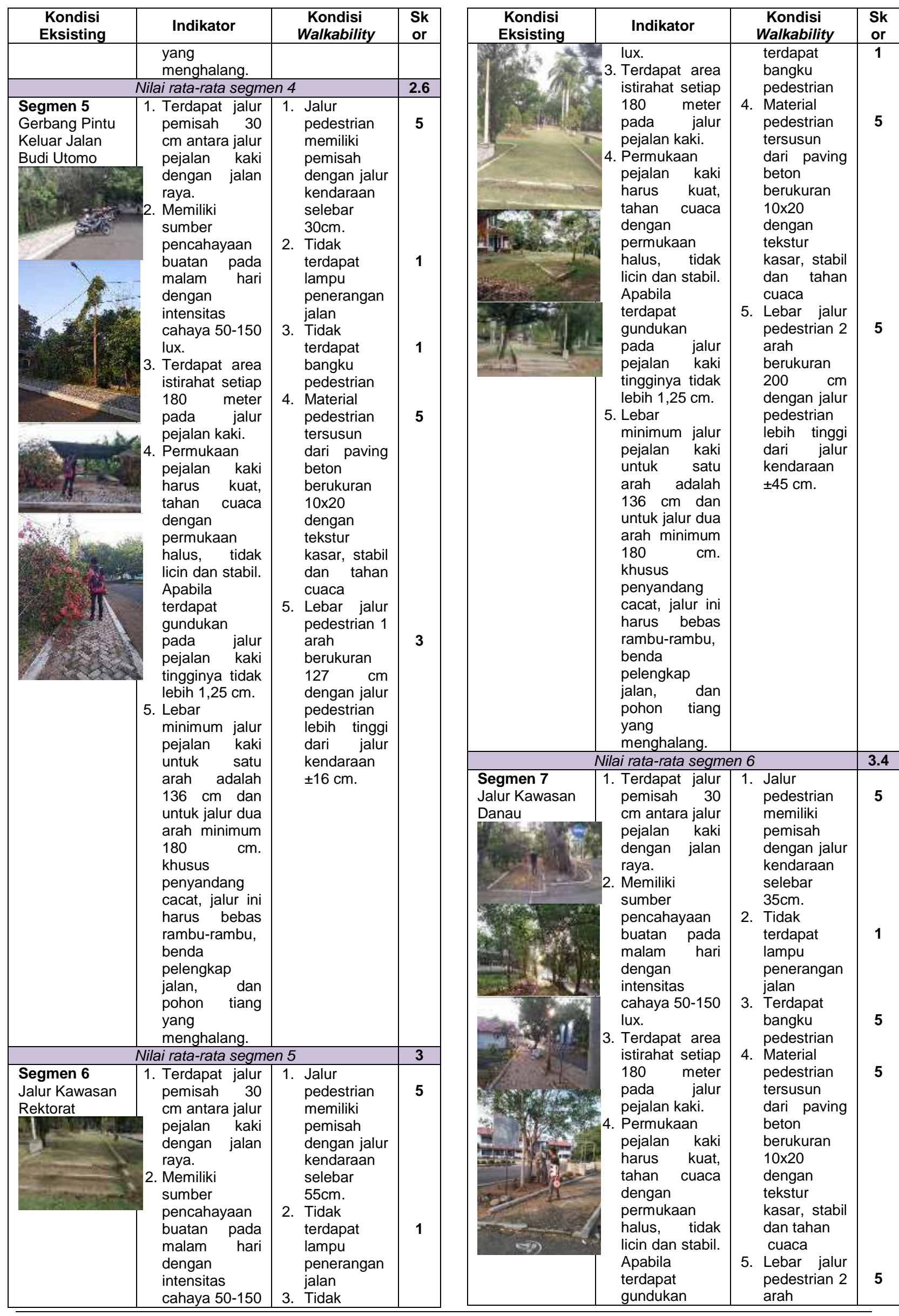




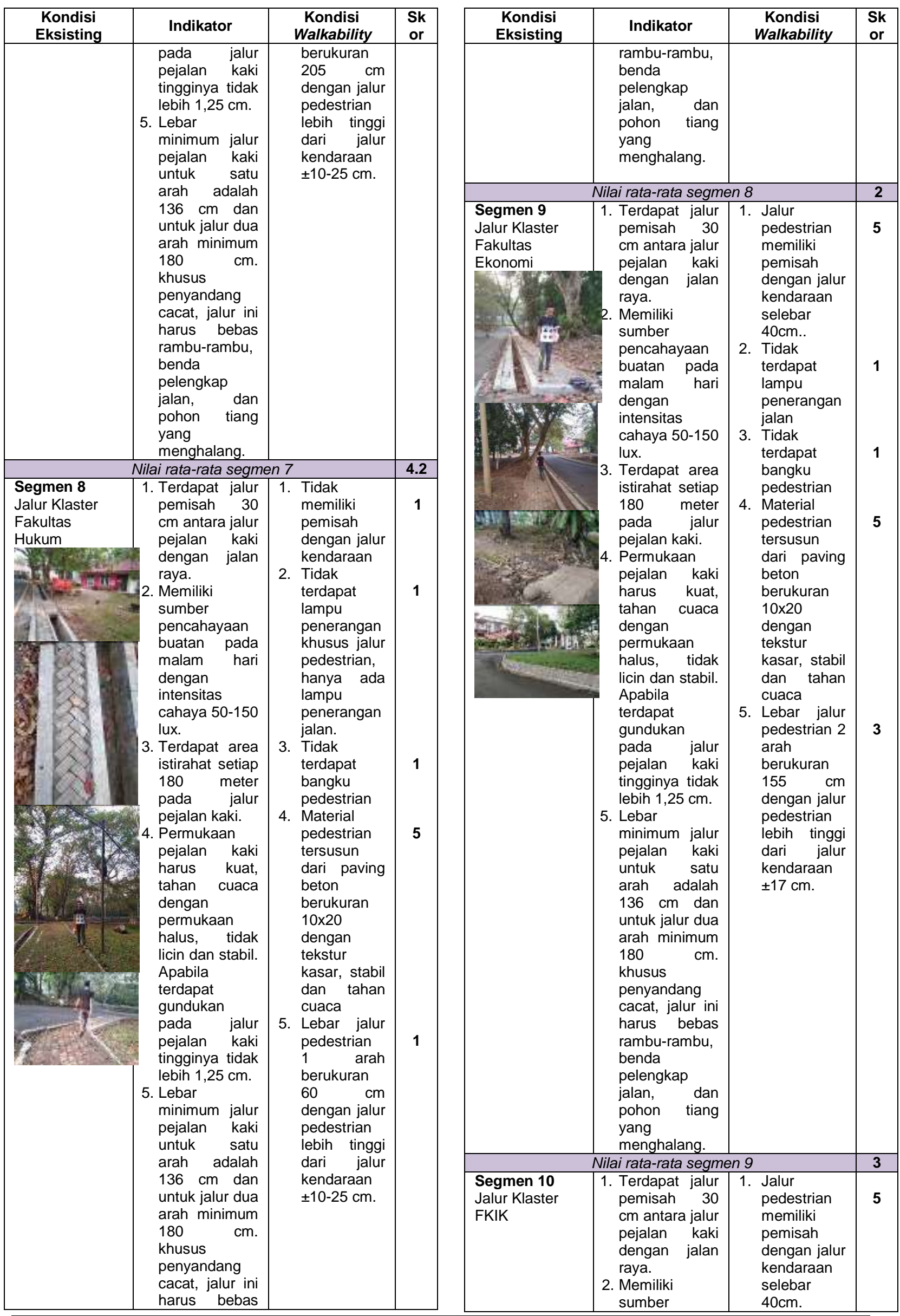




\begin{tabular}{|c|c|c|c|}
\hline $\begin{array}{c}\text { Kondisi } \\
\text { Eksisting }\end{array}$ & Indikator & $\begin{array}{c}\text { Kondisi } \\
\text { Walkability }\end{array}$ & $\begin{array}{l}\text { Sk } \\
\text { or }\end{array}$ \\
\hline & $\begin{array}{l}\text { pencahayaan } \\
\text { buatan pada } \\
\text { malam hari } \\
\text { dengan } \\
\text { intensitas } \\
\text { cahaya } 50-150 \\
\text { lux. } \\
\text { 3. Terdapat area } \\
\text { istirahat setiap } \\
180 \text { meter } \\
\text { pada jalur } \\
\text { pejalan kaki. } \\
\text { 4. Permukaan } \\
\text { pejalan kaki } \\
\text { harus kuat, } \\
\text { tahan cuaca } \\
\text { dengan } \\
\text { permukaan } \\
\text { halus, tidak } \\
\text { licin dan stabil. } \\
\text { Apabila } \\
\text { terdapat } \\
\text { gundukan } \\
\text { pada jalur } \\
\text { pejalan kaki } \\
\text { tingginya tidak } \\
\text { lebih 1,25 cm. } \\
\text { 5. Lebar } \\
\text { minimum jalur } \\
\text { pejalan kaki } \\
\text { untuk satu } \\
\text { arah adalah } \\
136 \text { cm dan } \\
\text { untuk jalur dua } \\
\text { arah minimum } \\
180 \text { cm. } \\
\text { khusus } \\
\text { penyandang } \\
\text { cacat, jalur ini } \\
\text { harus bebas } \\
\text { rambu-rambu, } \\
\text { benda } \\
\text { pelengkap } \\
\text { jalan, dan } \\
\text { pohon tiang } \\
\text { yang } \\
\text { menghalang. }\end{array}$ & $\begin{array}{l}\text { 2. Tidak } \\
\text { terdapat } \\
\text { lampu } \\
\text { penerangan } \\
\text { jalan } \\
\text { 3. Tidak } \\
\text { terdapat } \\
\text { bangku } \\
\text { pedestrian } \\
\text { 4. Material } \\
\text { pedestrian } \\
\text { tersusun } \\
\text { dari paving } \\
\text { beton } \\
\text { berukuran } \\
\text { 10x20 } \\
\text { dengan } \\
\text { tekstur } \\
\text { kasar, stabil } \\
\text { dan tahan } \\
\text { cuaca } \\
\text { 5. Lebar jalur } \\
\text { pedestrian } 1 \\
\text { arah } \\
\text { berukuran } \\
120 \quad \mathrm{~cm} \\
\text { dengan jalur } \\
\text { pedestrian } \\
\text { lebih tinggi } \\
\text { dari jalur } \\
\text { kendaraan } \\
\pm 20 \mathrm{~cm} \text {. }\end{array}$ & 3 \\
\hline \multicolumn{3}{|c|}{ Nilai rata-rata segmen 10} & 2.2 \\
\hline
\end{tabular}

Sumber : Analisis penulis, 2019

Keterangan:

Skor 5 : Aspek tersedia sesuai standar dan berfungsi dengan baik

Skor 4: Aspek tersedia sesuai standar namun tidak difungsikan

Skor 3: Aspek tersedia sesuai standar namun tidak sesuai fungsi

Skor 2 : Aspek tersedia tidak sesuai standar Skor 1 : Aspek tidak tersedia

Berdasarkan penilaian di atas, ditemukan bahwa pada segmen 1 memiliki skor tertinggi dengan perolehan data senilai 5 . Hal ini disebabkan pada segmen ini ditemukan kondisi pejalan kaki yang memenuhi syarat dari ketersediaan sarana prasarana serta bentuk jalur pedestrian yang memenuhi standar dan berfungsi dengan baik. Untuk segmen 2 dan 7 memiliki skor 4,2 dengan kategori sarana tersedia sesuai standar namun tidak difungsikan, sebab pada area ini belum terdapat titik penerangan lampu jalan. Pada segmen 3, 5, 6, dan 9 memiliki skor 3-3,6 dengan kategori sarana tersedia sesuai standar namun tidak sesuai fungsi, karena pada area ini ditemukan tidak terdapat titik penerangan lampu jalan serta kondisi lebar jalur pejalan kaki yang tidak memenuhi standar. Dan untuk segmen 4, 8, dan 10 memiliki skor terendah dengan nilai 2-2,6 yang disebabkan beberapa sarana yang tersedia tidak sesuai standar dari segi tidak ketersediaan titik lampu, tidak terdapat bangku pedestrian, belum adanya batas jalur pejalan dengan jalur kendaraan serta lebar jalur pejalan kaki yang terlalu sempit. Menurut pedoman fasilitas pejalan kaki PUPR menjelaskan bahwa ada beberapa standar yang perlu di diperhatikan dalam mengatasi permasalahan di atas, di antaranya 1). jalur pejalan kaki tidak langsung berdekatan dengan jalur kendaraan, 2). lebar jalur pejalan kaki yang memenuhi syarat serta aman dari jalur kendaraan dan 3). memiliki area jalur sepeda terpisah dari jalur pejalan kaki dengan batas warna yang mencolok serta perbedaan elevasi pada trotoar (Kementerian Pekerjaan Umum dan Perumahan Rakyat, 2017),

\section{KESIMPULAN}

Kondisi jalur pejalan kaki pejalan kaki yang ada di kawasan Universitas Bengkulu perlu adanya pembenahan di tinjau dari ketersediaan jalur pejalan kaki (jalur pejalan kaki) di ruas jalan dengan kondisi yang aman, nyaman, dan tanpa adanya konflik dengan pengguna kendaraan di samping jalur pejalan kaki. Beberapa cara yang dapat dilakukan untuk menyelesaikan permasalahan ini adalah 1). menyediakan jalur pejalan kaki yang terpisah dengan jalan kendaraan, 2). jalur pejalan kaki dengan jalur kendaraan bermotor terdapat ruang transisi, 3). ukuran jalur pejalan kaki saat pengguna troroar berpapasan, 4). ketinggian jalur pejalan kaki dari muka jalan, dan 5). ruang gerak saat berjalan lebih dari 2 orang. Selain itu untuk meningkatkan kondisi jalur pejalan kaki perlu memperhatikan ketersediaan sarana jaringan pendukung 
seperti tempat duduk, papan informasi, tempat sampah, marka, rambu, pagar pengaman, jalur hijau serta lampu penerangan (Suryobuwono \& Ricardianto, 2017).

\section{UCAPAN TERIMA KASIH}

Ucapan terima kasih peneliti sampaikan kepada Universitas Bengkulu sebagai selaku pemberi bantuan dana penelitian mandat Universitas yang bersumber dana DIPA tahun 2019.

\section{DAFTAR PUSTAKA}

Anggriani, N. (2009). Pedestrian Ways Dalam Perancangan Kota (Edisi 1). Surabaya, Indonesia: Yayasan Humaniora.

Auf, A. I. ... Rukayah, S. (2015). Pemilihan Pedestrian Ways Ditinjau Dari Persepsi Pengguna Di Koridor Jalan Gunung Sahari Jakarta Pusat. Pemilihan Pedestrian Ways Ditinjau Dari Persepsi Pengguna Di Koridor Jalan Gunung Sahari Jakarta Pusat, 15(1), 39-46. https://doi.org/10.14710/mdl.15.1.2015.3 9-46

GreenMetric, U. (2019). List of Universities in Each Region (2018) Rangking by Region - Asia.

Handayani, S. ... Isya, M. (2018). Tinjauan Sarana Dan Prasarana Jalur Pedestrian Di Kawasan Peunayong, Banda Aceh. Jurnal Arsip Rekayasa Sipil Dan Perencanaan, 1(1), 72-80. https://doi.org/10.24815/jarsp.v1i1.10357

Kementerian Pekerjaan Umum dan Perumahan Rakyat. (2017). Pedoman Bahan Konstruksi Bangunan dan Rekayasa Sipil: Perencanaan Teknis Fasilitas Pejalan Kaki. Indonesia.

PERMEN. (2014). Patent No. Nomor: 03/PRT/M/204. Indonesia.

Riani, Y. H. ... Ayuningtyas, R. A. (2018). Evaluasi Efektivitas Jalur Pedestrian di Jalan Ahmad Kani Kota Pontianak Berdasarkan Persepsi Masyarakat. Jurnal UMahasiswa Teknik Sipil UNTAN, 5(3), 1-12.

Suryobuwono, A. A., \& Ricardianto, P. (2017). Perencanaan Trotoar Dalam Rangka Peningkatan Keamanan dan Keselamatan Pejalan Kaki. Jurnal Manajemen Transportasi \& Logistik, 4(3), 335-346. 